\title{
Research on Transformation and Upgrading of the Logistics Enterprises Based on Innovation Efficiency
}

\author{
Yuqin Wang \\ Xi 'an International University, Shaanxi Xi' an 710077, China
}

Keywords: innovation efficiency, logistics enterprises, transformation and upgrading.

\begin{abstract}
On the basis of development of the Internet, the Internet of things, logistics development is facing great opportunities and challenges, and logistics enterprises are facing the problem of transformation and upgrade, too. Nowadays, the logistics industry in the new era has become the industry which combines with labor and information. Under this development situation, logistics enterprises faces the problems that labor cost is rising and how to improve the using efficiency internally, and there is severe competition externally. Therefore, logistics enterprises must carry out transformation and upgrading, and gradually achieve the upgrading oriented by innovation and efficiency in order to expand development space and create greater economic interest. Based on it, this paper makes an analysis on logistics enterprises transformation and upgrading oriented in innovation and other problems, and puts forward some suggestions and views combined with examples.
\end{abstract}

\section{Introduction}

Under the background of the development of modern society, China's economy has entered a new period of development, products in all walks of life can flow, warehouse and so on through many channels. Thus, the transformation and upgrading of logistics enterprises become an inevitable trend. However, how to carry out the transformation and upgrading for logistics enterprises, and realize the innovation and efficiency, are the problems that most of the logistics enterprises must consider. Only through innovation output and innovation efficiency management continuously, competitiveness and vitality of logistics enterprises can enhance.

\section{The situation about the logistics enterprises transformation and upgrading oriented in innovation and efficiency}

According to the survey data and statistics, by the end of 2014,the total logistics in China has increased by $8 \%$ which compared with 2013 , the logistics industry has grew by about $9 \%$, reaching over 34 billion[1]. The more important reason of the stable development of logistics industry is that the enterprises made an continuous innovation on technology and management in the process of transformation and upgrading. The following makes a detailed analysis on the two aspects of technology and management from the logistics enterprises innovation and upgrading.

In the process of logistics enterprise transformation and upgrading, in terms of the technical level it has gotten a lot of development and innovation has greatly promoted the logistics circulation speed [2]. The main factors that lead to the status are the following points:

(1) Improvement of the network information technology, such as the Internet of things, cloud computing and other factors: in favor of computer technology, all kinds of the logistics enterprises have more platforms, enterprises can publish correlative information through the computer platform, so that increasing the number of enterprise business, expanding the logistics quality. At present, most of logistics enterprises devote to the coordinated development of online and offline, the cooperation between logistics enterprises and the merchants, manufacturers and terminal clients is more convenient and faster. Taking the Jingdong mall as an example, since the launch of Asia one, its logistics service capability has reached the first-class level, achieved sorting and handling goods 16000/hour. In addition, the logistics APP has become a popular way, it can grasp the relevant 
information about logistics in time, fully satisfy the needs of customers. In conclusion, the application of network information technology makes the development of intelligence and information come true.

(2) Factors of refrigerated, storage technology: in logistics industry, logistics transportation and integrity, freshness all need to be guaranteed. Therefore, logistics enterprise contributes to improving the technology continuously. So far, it has emerged a cold chain logistics model, which is based on the freezing technology, takes cold storage technology as method in logistics. Besides, combination with refrigeration and container transportation technology also has the logistics efficiency greatly improved.

In the logistics enterprises transformation and upgrading, management innovation and management efficiency mainly develop towards the direction of management system. During that, many logistics enterprises are strengthening their own delivery systems, building logistics network platforms. In fact, there are still some problems which are the high cost,the extensive operation ways in the internal development of logistics industry. So, innovating the logistics management is essential. Perfecting the delivery system, building the logistics network platform are able to accelerate the transformation and upgrading of the logistics enterprises in a great degree [3.4].

Taking the construction of network platform and management of logistics enterprise for example, the industrial park is the common management development model of logistics industry. This model could reduce the cost of the management and transportation in the past greatly. However, the weakness of the park model is also highlighted under the background of the economic new normal that makes the level of resource allocation be in trouble resulting from the local protectionism in the internal park logistics enterprise. Thereby, most logistics enterprises enhance internal management which combine with information technology on the basis and principle of promoting the efficiency of resource allocation, and causing a variety of platforms and innovative business models.

\section{Analysis on the logistics enterprises transformation and upgrading oriented in innovation efficiency}

In aspects of technology and management, the logistics enterprises transformation and upgrading have conducted a variety of innovations, and transportation, operation efficiency have been improved in a certain extent. As for the predominant problems of logistics enterprises transportation and upgrading and itself, which actually face with some bottlenecks, it's the analysis in followings in the case of bottlenecks and problems.

Because the logistics needs to transform goods from the origin to the destination, in the process of transporting, it includes portage, storage, purchase, transportation and other more detailed work, these work can make an influence on delivery quality, speed and time. Many logistics enterprises have adopted to the intelligence and information management in order to improve the service quality of transporting goods and create more benefits, at the same time, innovated technology.[5] But due to relatively high cost of intelligence and information, and diversification and individuation for client's needs, the logistics enterprises of its intelligence and information logistics enterprises are relatively backward, only a few of logistics enterprises reach a relatively high degree on information and intelligence.

All kinds of industries development in China are related to tax, tax is one of the factors which consist of cost in the logistics industry. As to the related tax policies, the purpose of replacing the business tax with a value-added tax is that reducing the limit of industry and enhancing the development vitality. Nevertheless, according to the survey and data by China Federation of Logistics and Purchasing show that the tax doesn't decrease after replacing the business tax with a value-added tax instead of increasing. On the basis of estimation, the tax burden of the logistics enterprises increased by an average of about $120 \%$. The tax expenditure of logistics enterprises in 2013 increased by an average of 37.3\%, there is no doubt that tax problem is still the main problem for logistics enterprises. It is bad for developing logistics enterprises. In addition, the toll is continuously high, that accounted for $9.1 \%$ of the transportation cost. $30.6 \%$ enterprises reflect the highway toll standard is extravagant, $28.8 \%$ think that the overrun fee is unreasonable, and there are 
other problems just like inconsistent charges, overdue or deferred charges and so on. It can be known that it is still hard for logistics enterprises to make innovations and effective transformation and upgrading.

\section{Suggestions about logistics enterprises transformation and upgrading oriented in innovation}

According to the above analysis, if the logistics enterprises expects to transform and upgrade, carry out the improvement of innovation and efficiency in industry enterprises, it can follow the points:

The logistics industry has produced some of the more advanced technologies and management models, this is beneficial to transportation and upgrading greatly. In order to improve the intelligence and information degree of logistics park business, reduce logistics cost and realize the refined operation, that can strengthen the linkage and integration among logistics enterprises, build the perfect industry chain. In the industrial chain, transportation, storage and suppliers can be refined so that providing integrated service for users or clients, and form a new model of "Internet plus logistics" gradually.

The transformation and upgrading of logistics enterprises need to the support of the government, especially decreasing taxes. Specifically speaking, taking corresponding measures to reduce the tax [7]. As to that, it can cancel the part repeated tax on the basis of the replacing the business tax with a value-added tax, meanwhile, can appropriately adjust to the bridge, road and other fees on the logistics transportation, reduce the charges on logistics enterprise transportation specification.

Furthermore, in order to support the development of logistics enterprises, the government can implement so certain preferential policies that enhancing the cooperation and connection around all logistics enterprises, then achieve the sharing about data, resources and others with the help of the computer network platform.

One of the most important parts of logistics is goods transportation, the storage technology, management, fees and others are the keys in the process of transportation [8]. In order to ensure that the goods transport smoothly, realize the lowest fee of transportation, transport, it can shorten the transport time extremely to improve the efficiency of transportation. During the management of transportation based on these factors, the logistics enterprises can choose the flexible transformation ways, also can use a variety of common transportation, then can control and grasp the transportation process with the benefit of the computer network.

The current logistics enterprises are still focused on the extensive management. Whatever the human resources management on the internal labor, position, or the internal operation, still need to be improved. To optimize and prefect the internal management of logistics enterprises that can take the following measures: (1) pay more attention to optimizing the internal human resources, building a mechanism which encourages the staff to create. For example, adopting the send commission method to fully mobilize the enthusiasm and innovation of the logistics staff; (2) adjust to the structure management of the internal enterprise operation process, under the support of technology, making an adjustment to the transportation, procurement and other parts that combines with the practical situation of the enterprise.

\section{Conclusion}

To sum up, the transformation and upgrading of logistics enterprises are affected by several important factors, that include the related information, cold storage technology, include the model of management. It is worth nothing that the labor cost, tax cost are also the very important factors of the logistics enterprises. The following factors which mentioned are essential to make innovation and improve the efficiency for the logistics enterprises transformation and upgrading. This article also puts forward some suggestions such as strengthening the linkage and connection among logistics industries, making transportation model flexible and realizing diversification and so on. Wish that these suggestions can provide certain reference for the development of logistics 
enterprises.

\section{Acknowledgements}

This paper is the social science fund project of Shaanxi province in 2016, Serial No. $2016 \mathrm{R} 045$.

\section{References}

[1] Zhongchao Hao. "The study of [J]. Business transformation and upgrading of the logistics enterprises Internet plus" era (economic theory), 21:23-24, 2015

[2] Wenqiang Yu. Research on Transformation and Upgrading of Logistics Enterprises Based on Innovation Efficiency [J], Logistics Engineering and Management, 07:5-7, 2016.

[3] Jiaqiang Tao. The Labor Cost and Efficiency of China's Logistics Enterprises and the Transformation and Upgrading-the Data Analysis of China's Listed Logistics Enterprises in China [J].China Business and Market , 10:66-72, 2016.

[4] Wanhua Zhao, Yong Zhang. The Necessity Analysis and Countermeasure Research of Tangshan City Iron and Steel Logistics Industry Transformation and Upgrading [J]. Intelligence, 27:337, 2015.

[5] Xiukui Wu. Existing Problems in Transformation and Upgrading of Operational Management System of Traditional Logistics Enterprises. [J]. Logistics Technology, 13:92-93+169, 2015.

[6] Xiujing Xue, Yonghua Lu. The Research on the Logistics Enterprises Transformation and Upgrading in Jinhua City Based on the Background of Information [J]. The Management and Technology of Small and Medium-sized Enterprises. (On the ten days), 05:237-238, 2012.

[7] Yincheng Xie. The Research on Logistics Industry Upgrading Path and Policy Tendency under the Internet of Things Environment [J]. Business Times, 36:26-27. , 2012

[8] Yang Yang. The Research on the Logistics Enterprise Transformation and Upgrading Based on IOT. [J]. Logistics Technology, 03:31-32+42, 2013. 